\title{
TIME CONSISTENCY AND SELLER COMMITMENT IN INTERTEMPORAL MOVIE DISTRIBUTION: AN EMPIRICAL STUDY OF THE VIDEO WINDOW *
}

\author{
DAVID WATERMAN $\dagger$
}

ANDREW A. WEISS $\ddagger$

We study the determinants of the 'video window' (the interval between a movie's theatrical and video releases), based on a sample of 1,157 films released on video between 1988 and 1997. For subsets of films having shorter theater (cinema) run lengths (1 to 17 weeks), windows were generally longer than, and largely invariant to, measures of the time required to exhaust the theater market. One interpretation of our results is that U.S. movie distributors resolved a time consistency problem by coordinating their behavior to maintain longer windows than would have otherwise resulted, but different explanations are also plausible.

*We thank Home Media Retailing (formerly Video Store Magazine) and A.C. Neilsen for providing data. Michael Baye, Paris Cleanthous, Liran Einav, Shane Greenstein, Tong Li, Tom Lyon, Eric Rasmusen and participants in presentations at the International Industrial Organization Conference, the American Economic Association Annual Meetings, and Telecom Paris Tech provided valuable comments on earlier versions of the paper. More extensive analysis and citations are available in Waterman, Weiss and Lee [2008]. See also Waterman [2005].

†Authors’ affiliations: Dept. of Telecommunications, Indiana University, Bloomington, Indiana, U.S.A.

e-mail:waterman@indiana.edu

$\ddagger$ School of Economics, The Australian National University, Canberra, Australia.

e-mail: Andrew.weiss@anu.edu.au 


\section{INTRODUCTION}

The practice by which movie distributors sequentially release major theatrical films in different 'windows' - first theatres (cinemas), followed months later by DVD, then pay-per-view (PPV), etc. - has been widely identified as a form of intertemporal price discrimination (Conant [1960]; Owen and Wildman [1992]). ${ }^{1}$ As Coase [1972] observed, however, the seller of a durable good (such as a movie) must have a way of committing to consumers that there will be some length of time before the price will be reduced, in order to preserve market segmentation.

Movie distributors appear to face such a time consistency problem in deciding where to set the 'video window,' defined as the time interval between a movie's theatrical release and its video release. Consumers' expectations of video release dates are evidently formed by their perceptions of some average video window in the past. Under these circumstances, the distributor of a given film might benefit from relying on those expectations to attract the largest possible crowd at the theater, and then immediately releasing the film to video when the theater audience falls off (within one to two months for most movies). Industry executives have publicly acknowledged this temptation. ${ }^{2}$ The earlier the video release, the fresher is the film and its theatrical ad campaign, and the lower are the distributor's inventory costs. This logic implies that in a competitive environment, video windows would tend to collapse in the absence of some kind of a commitment device. In the U.S., there is anecdotal evidence of an attempt in the mid-1990's by the National Association of Theater Owners to coordinate a minimum video window, and studio executives have periodically warned competitors via the trade press that shorter windows threaten the stability of the movie release system. In Europe, video window agreements between theater and distributor trade associations are often more explicit and, in a few countries, minimum windows have been mandated by law (Paul Kagan Associates [1994]; Screen Digest [2002]).

In this paper, we empirically investigate distributor behavior in video window setting, using a database of 1,157 theatrical movies released on video in the United States between January 1, 1988 and December 31, 1997. During this period, the six or seven largest U.S. studios controlled 80 to $90 \%$ of the US movie box office and together distributed 150 to 200 major films per year. Is there evidence, we ask, that these or other distributors successfully committed to longer windows than would result from a competitive model in which firms independently set windows without regard to their effect on consumer expectations? Our results suggest the plausibility of sustained industry coordination in window setting during our study period, but alternative explanations are also possible.

Following a brief review of previous studies, we introduce our database and examine descriptive data for possible evidence of coordination. We then proceed to our econometric analysis, followed by discussion and conclusions.

\footnotetext{
${ }^{1}$ Owen and Wildman (1992) and Waterman (2005) show evidence that realized prices per-viewing paid by consumers generally decline throughout the release sequence, as do per capita distributor gross revenues, suggesting intertemporal discrimination. Product quality segmentation is also evident. Other strategy may be involved, such as the building of word-of-mouth and the collection of information about future demand (DeVany and Eckart 1991). In a study of book publishing, a media industry having an analogous distribution practice of releasing books in hardback and later in soft cover, Clerides (2002) used an industry database to show that price-cost margins imply intertemporal discrimination.

${ }^{2}$ Seth Goldstein, "Home video finds a lower spot on media food chain," Billboard, Oct. 25, 1997, p. 72; "On the Record: Studio Executives and Directors Overwhelmingly Support Preservation of the Theatrical Window, National Association of Theater Owners, December, 2006 (www.natoonline.org; downloaded January, 2007).
} 


\section{BACKGROUND}

The original insight of Coase [1972] (commonly known as the 'Coase conjecture') was formalized by Bulow [1982]. These and numerous later authors have identified a variety of commitment devices, such as leasing the product, committing to limit future production, 'best price' provisions and reputation, that can resolve the time consistency problem and thus preserve monopoly pricing power of sellers. Gul [1987] and Ausubel and Denekere [1987] present game theoretic models in which competing durable good sellers (or potential entrants) discipline each other to maintain prices above cost. Systematic empirical studies of how firms cope with time consistency, however, appear absent from the literature.

In the movie case, Owen and Wildman (1992) hypothesized several factors likely to affect video window lengths, such as the interest rate and VCR penetration, but they did not consider time consistency. Prasad, Bronnerberg and Mahajan [2004] developed a theoretical model of product timing that includes consumers' video window expectations, and concluded that myopic window setting by an individual movie distributor may result in an equilibrium window that is shorter than the industry optimum.

Using German data, Frank [1994] found that video windows had become shorter as VCR's diffused, and were longer for more successful movies. But he excluded movies with relatively short theater runs to avoid potential bias from a 'gentleman's agreement' between distributors and German cinema associations that the video window should be at least six months. Nelson, Reid, and Gilmore [2007] acknowledged the time consistency issue in an empirical investigation of trends in the 'out-of-market gap' for DVD's (the interval between theater closing date and DVD release), but they did not explore commitment devices. Using 1998-2005 data, they reported a decline in the gap as DVD penetration increased over the period; and among other results, they found that the gap decreased with the length of a film's theater run.

\section{DATA}

Our main data source is the "A Title List" maintained by Video Store Magazine, a leading trade publication, which includes video market information on all movies released during our 1988 to 1997 study period which sold at least 50,000 units at the wholesale level (the great majority of theatrical films of economic significance). We supplement these data with the A.C. Nielsen EDI electronic database, which contains detailed theater market performance information for virtually all movies released in theaters in the United States since 1986.

Beginning with 1833 A Title List movies released during the period, we eliminated 182 that earned less than $\$ 1$ million at the box office or whose maximum weekly theatrical exposure did not reach at least 24 screens nationally, 272 movies missing production cost information, 205 movies due to inconsistent or other missing data, and 17 movies in which the video window was in excess of 365 days (on the rationale that such long windows might reflect inadequate financial resources of the distributor or perceived changes in market conditions that rendered a video release unviable). This process results in our sample of 1157 movies.

During the 1988-1997 period, theaters and video were the dominant sources of domestic distributor revenues from the release of theatrical features. Video accounted for between $38 \%$ and $50 \%$ of the total, generally rising over the period. Theater rentals accounted for between $25 \%$ and $36 \%$, generally declining over time. Income from hotel, airline and other media releases that occurred 
between the theater and video releases were very minor, accounting for less than $1 \%$ of the total. The same was true for PPV, which generally occurred 45 to 60 days after video, and earned less than $2 \%$ of studio revenues by the end of this period.

In about 1997, DVD rapidly began replacing VHS as the prevailing video format. Our study thus focuses almost entirely on video release in the VHS format. The change in video technology resulted in a fairly dramatic shift toward "sell-through" studio pricing strategies that promoted video sales over rentals. ${ }^{3}$ Press reports also indicate that video release dates in the later 1990s were often delayed due to greater time intervals required to put together "bonus" DVD materials, such as deleted scenes and interviews. We did not attempt to include post 1997 data in our models, but we briefly discuss the video window after 1997 in the Conclusion.

\section{Descriptive Analysis}

Table 1 gives descriptive statistics for the video window (Window) over the period 1988 to 1997. The means and medians are close to the overall median of 180 days throughout the period, although some downward trend in both measures is apparent.

Place Table 1 approximately here.

There is considerable variation in window lengths within each year, as evidenced by the ranges and standard deviations. With exception of one release in 1991 with a window of 14 days, the windows for all movies in the sample are at least 56 days.

Figure 1 illustrates the distribution of windows using a representative year, 1996. As indicated by Table 1, the distribution is more clustered around the mean than the normal distribution; the ratios of the interquartile ranges (IQRs) of the data to the IQRs of the normal distributions with the same standard deviations are generally less than one.

Place Figure 1 approximately here.

The dispersion in window lengths suggests little evidence of a minimum window benchmark. Practical realities, however, likely constrain the precision of setting window lengths. Similar to the process of setting theatrical release dates (Einav, 2007), video distributors typically float potential video street dates to their large retail buyers in advance of committing to a final date. Distributors then commonly make adjustments, ranging from a week to a month or more, to avoid undesirable competitive conflicts. We cannot tell how much of the observed randomness is noise from the interactive street date setting process.

Next, Table 2 shows means and medians for theater run lengths and the out-of-market gaps. TheaterRun, defined to include virtually any theatrical activity, ${ }^{4}$ averaged about 12 weeks. The average out-of market gap, defined as

$$
\text { Gap }=\text { Window }- \text { TheaterRun }
$$

\footnotetext{
${ }^{3}$ See Mortimer (2007) for detailed discussion of video release strategies.

${ }^{4}$ TheaterRun is defined to be the total number of days after theater opening for which any revenues are reported by EDI. Data are reported only by one week intervals, and are thus lumpy to that extent.
} 
was nearly as long. That is, there was a relatively long average period during which movie distributors withheld their movies from the marketplace (except for airlines and hotels) before their video release.

Place Table 2 approximately here.

An alternative definition of the theater run is the time by which $95 \%$ of the eventual total of box office receipts have been received (TheaterRun@95\%Rev). That definition acknowledges that long theater runs can often be accounted for by relatively insignificant "subrun" theater engagements, often at discount prices. Under this alternative definition, the mean theater run is much shorter and the corresponding out-of-market-gap (Gap@95\%Rev) is much longer, averaging about 17 weeks over the period. Furthermore, the mean runs and gaps are generally constant over time.

The pattern in Table 2 across years suggests a negative bivariate relationship between the out-ofmarket gap and the theater run length for the 1157 movies. Figure 2 gives another view of that, showing the relationship between the gap and theater run for all movies, regardless of year of release. Note that the gap averages over 100 days for movies with 12 week or shorter total theater runs (the dashed line) and declines almost monotonically to zero for movies with 26 week runs. The Gap@95\%Rev variable (the solid line) also declines steadily with the theater run length, but noticeably more mildly.

Place Figure 2 approximately here.

Could the out-of-market gaps indicated in Figure 2 be explained by institutional features of movie distribution? Distributors generally announce video release dates one or months in advance to allow time for ordering, manufacture, shipping and advertising. These "video announcement" periods may account for some of the gap. Studios are also plausibly constrained to wait until a theater release is substantially completed before making the video announcement, in order to avoid undermining theater demand. ${ }^{5}$

We obtained announcement period information for a sample of 242 movies released between 1994 and 1996. ${ }^{6}$ The mean period was 63 days, with relatively low standard deviation of 27 days. It is evident from Figure 2, however, that the observed gaps are greater than could be accounted for by this time period, especially for shorter run movies. Also, many announcement periods were shorter than 63 days, and about half of the 242 announcements were made before the theater closing date. That suggests that the conclusion that actual gaps are longer than announcement periods could account for is conservative.

\section{The Model}

To further investigate window setting behavior, we estimate a reduced form version of an underlying theoretical model of supply and demand. In that theoretical model, the profits for the individual distributor from the combined theater and video market for a given movie depend on price-cost margins, the producer's discount rate and the consumer demand functions for theater and video. Consumer demands depend on the expected video window, a time discount rate, prices, penetration of home video hardware, seasonal factors and individual movie characteristics such as

\footnotetext{
${ }^{5}$ See, for example, S. Hettrick, "Window to Wonder," Daily Variety, Sept. 19, 2002, p. 12.

${ }^{6}$ These data were provided to us by the National Association of Theater Owners.
} 
production investments, marketing strategy and movie type. A shorter expected window, for example, would be expected to increase video demand at the expense of theater demand.

Consumers anticipate the video window of a particular movie based on their experience with windows in the past. At least potentially, the full array of movie-specific and other variables that enter the profit function of distributors also affects the consumer's expected window for that movie.

Further assuming that expected windows are equal to actual windows in equilibrium, we derive the following basic operational model:

$$
\begin{aligned}
\text { Window }_{i}=a * & \text { VCRPen }_{i}+b^{*} \text { RealInt }_{i}+c^{*} \operatorname{In}\left(\text { ProdCost }_{i}\right)+d * \operatorname{In}\left(\text { ProdCostD }_{i}\right) * \text { RealInt }_{i} \\
& +e^{*} \operatorname{In}\left(\text { BoxTotalD }_{i}\right)+f * \ln \left(\text { MaxScreens }_{i}\right)+g * \operatorname{IndDum}_{i}+h^{*} \text { SellThrough }_{i} \\
& +j * \text { Genre }_{i}+k^{*} \text { Month }_{i}+m^{*} \text { TheaterRun }_{i}+e_{i}
\end{aligned}
$$

where $i$ identifies movies. Variable definitions are given in Table 3.

Place Table 3 approximately here.

The key variable of interest is TheaterRun. In the absence of any commitment (or institutional constraint), a movie's optimal video release date will occur when net theater revenues per day diminish to the point that higher total net revenues can be earned by adding the video revenue stream (as shown by both Frank (1994) and Prasad et al. 2004). Although the profitability tradeoffs of these revenue streams are not observed, some positive relationship between theater run length and the video window is implied.

At the other extreme, all distributors might coordinate video window setting as if they were a monopoly; that is, by setting video release dates such that consumers' expected future windows maximize expected industry profits from both the theater and video markets for all movies combined. In this scenario, no relationship between the theater run length and the video window is necessarily implied.

Next, VCRPen proxies for the potential of the video market relative to the theater market. The distributor's marginal tradeoff between theater versus video revenues shifts in favor of shorter windows as VCR penetration rises (Frank, 1994). RealInt represents the distributor's time discount factor; higher interest rates should induce shorter windows.

The other variables in equation (2) are movie specific. Higher film production cost, ProdCostD, may induce a distributor to have a shorter window if capital market constraints are significant. The interaction term, RealInt* $\ln ($ ProdCostD), reflects the further expectation that if capital markets are imperfect, pressures to shorten windows to recoup costs of relatively expensive movies may be greater. IntDum indicates the approximately $6 \%$ of cases in which there is no Motion Picture Association of America (MPAA) member involvement in the movie's theatrical or video release. Higher values of MaxScreens should affect windows negatively since other things equal, geographically broader distribution should exhaust the theater market sooner. SellThrough is a dummy indicating a sales oriented video release strategy used by studios for a relatively small number of high budget, high market potential movies during the period. The effect of theater market performance (BoxTotalD) on windows is difficult to predict. Substitution should imply a negative effect on video demand, but high box office reports may be a positive signal to the video market. Genre proxies for movie characteristics and Month of release for seasonal factors. Logarithmic forms for some variables in (2) reflect assumptions of diminishing marginal effects. 
We split the full sample into three approximately equal segments over which the commitment issue may be of differing relevance: movies having theater run lengths of (a) under 11 weeks; (b) 11 to 17 weeks, and (c) greater than 17 weeks. ${ }^{7}$

Commitment may be most relevant for those movies with a relatively short theater run and we aim to be conservative by using the under- 11 week segment. A film that stays in theaters for 10 weeks (70 days), followed immediately by the mean video announcement period of 63 days, could be released to video in 133 days after the theater release without risk of diminishing theater demand. That is well before the 185 day mean window period for the full 1157 sample, implying that, without commitment, video release decisions could reduce consumer expectations of minimum windows in the future. Successful commitment thus implies that the TheaterRun coefficient will have no significant effect on Window in the under-11 week theater run segment.

At the opposite extreme, for movies having theater runs greater than 17 weeks, the addition of the minimum 18 week theater run (126 days) to the 63 day mean announcement period gives 189 days, approximately the mean window. For this portion of the sample, seller commitments are of questionable relevance. For movies in the intermediate 11-17 week interval, the relevance of commitment is also uncertain. In sub-samples (b) and (c), a positive and significant relationship between TheaterRun and Window would be consistent with either a commitment or no commitment case.

As noted above, TheaterRun may not be fully determined at the time the video release date announcement is made. The substitution of TheaterRun@95\%Rev would appear to address that problem, as well as to provide a potentially more realistic measure of the distributor's theater run length constraint. ${ }^{8}$ We estimate models with both theater run variables.

\section{Results}

Tables 4 and 5 report OLS results from estimating equation (2) using TheaterRun and TheaterRun@95\%Rev, respectively. Each table contains results for four models: for the full sample and for each of the three theater run length sub-samples. We suppress the Genre and Month coefficients.

Place Tables 4 and 5 approximately here.

Signage of variables other than the theater run measures are generally as expected, or the variables are insignificant, and we do not discuss them further here. Of most interest are the coefficients on the theater run variables. For the full sample models, 1 and 5, both theater run length measures are strongly significant and positive. The coefficients can be thought of as combinations of the values in the three sub-samples.

Coefficients in both the under-11 week and 11-17 week segments are close to zero and insignificant in 3 of 4 cases (models 3, 6, and 7), consistent with the commitment hypothesis. The coefficient on TheaterRun in the under-11 week segment in Model 2 is marginally significant, but negative, the

\footnotetext{
${ }^{7}$ Theater run lengths were available only at one week intervals.

${ }^{8}$ Ideally, we also would use a variable representing the actual box office performance of the movie at the time that a window date decision is made or at least announced. However, $90 \%$ of street date announcements are made after at least $95 \%$ of box office receipts are in - a point from which the distributor is undoubtedly able to make an accurate estimate of the eventual box office receipt total.
} 
opposite direction that would be expected from a "no commitment" model. The positive and strongly significant coefficients on the theater run variables in the over-17 week theater run segments (Models 4 and 8) suggest that longer theater run lengths are beyond a meaningful commitment level and at that point simply "push" the video release date out in time.

The regression results can be interpreted in terms of the alternative window measure, the out-ofmarket gap. Substituting equation (2) into equation (1) shows that the implied coefficient on TheaterRun in the equation for Gap is equal to $m-1$, where $m$ is the coefficient on TheaterRun in equation (2). The same applies to the equation for the 95\% of revenue gap variable, Gap@95\%Rev. Table 6 gives the implied coefficients on the theater run variables. ${ }^{9}$ All derived coefficients on the TheaterRun and TheaterRun@95\%Rev variables are negative and strongly significant. Mirroring the Window model results, these coefficients are very close to -1 for the under- 11 week and 11-17 week run length segments for the truncated "95\%Rev" models. An increase in the theater run is thus associated with an equal decrease in the out-of-market gap.

Place Table 6 approximately here.

These results were robust to a variety of alternative model and time period specifications and to dropping the $\$ 1$ million/24 theater screen minimum restrictions. Table 7 gives the results from applying three specification tests to the models. The tests are: (1) the White test for heteroskedasticity based on squared terms but not cross-products, (2) the RESET test, and (3) the F-test for the null hypothesis that the coefficients on the five variables, \{RealInt, $\ln$ (ProdCostD), RealInt*In(ProdCostD), $\ln ($ BoxTotalD), $\ln ($ MaxScreens)\}, are all zero.

Place Table 7 approximately here.

Focusing on Models 2, 3, 6 and 7, we see that these estimations do not reject the null in the White and RESET tests (tested at the 5\% level). In the models with our truncated measure of the theater run (Models 6 and 7), the set of five variables are jointly insignificant (tested at the $5 \%$ level). The model appears to 'break-down' in the case of the movies with longer theater runs, and consequently in the model on the full sample.

\section{Discussion and Conclusion}

Results of our econometric analysis using data for 1988-1997 show that for a subset of movies having theater run lengths sufficiently short so that seller commitment is likely to be a relevant issue (under 18 weeks, or 7 to 126 days), video windows were longer than the time required to exhaust the theater market and were generally invariant to the theater run length. A plausible interpretation of this result is that U.S. movie distributors coordinated their behavior to maintain longer video windows than would have resulted from an industry in which distributors competitively set windows without regard to their effect on consumer expectations of future window lengths.

Actual windows for individual movies, however, showed a relatively wide dispersion around the median window of approximately 26 weeks. This dispersion might partly be explained by random variations induced by the interactive process of setting video release dates. In any event, decision making flexibility for individual movies is clearly suggested by the data.

\footnotetext{
${ }^{9}$ The linear transformation does not affect the standard errors, but the t-statistics change. In the Window models, the tstatistics test the null hypothesis, $H_{0}: m=0$; whereas in the Gap and Gap@95\%Rev models, the t-statistic tests the hypothesis $H_{0}: m-1=0$, or $m=1$.
} 
Other interpretations of our results are also plausible. An implicit assumption of the coordination hypothesis is that consumers do not infer that if a particular distributor shortens the windows for one or more of its films, then it is more likely than other distributors to shorten windows in the future. While this assumption appears plausible, the six or seven major distributors averaged 20 to 30 releases per year, and we cannot dismiss the argument that independent behavior by these individual firms would by itself serve as a commitment device. These distributors also are known to space out their theatrical releases during the year, and it may be that having consistent video windows serves as a device to preserve this spacing in the video market.

We also acknowledge shortcomings in our statistical analysis. First, representation of the decision making process with reduced form models may be flawed. For example, the effects of theater run lengths on window decisions may be more complex than our models can represent. More broadly, the true structural model of window decision making is not necessarily one way cause and effect. For example, distributors may make theatrical release decisions with a tentative video street date in mind.

Although we were not able to rigorously distinguish among alternative interpretations of our results, this study represents a first empirical attempt to explain how firms may cope with time consistency in a competitive industry. The industry coordination interpretation is broadly consistent, at least, with the theoretical models by Gul (1987) and Ausubel and Denekere (1987) that study commitment by means of discipline within a competitive environment.

Looking back in time, our research also has implications for understanding movie industry behavior prior to U.S. v. Paramount Pictures et al. (1948). In this early era of the industry, local cartels of theater owners and the major film distributors in some U.S. cities overtly colluded to control a movie release system involving up to 11 sequential runs at progressively lower priced theaters (Conant, 1960). Individual theaters were assigned to a tier (e.g., "A pre-release", "B general release", etc.), had a minimum admission price, and a set "temporal clearance" (a period of time, generally one to three weeks, during which individual theaters were guaranteed that no later run theater would exhibit a movie until after their run had been completed). These precursors of the modern multi-media movie release system were held illegal in Paramount, but whatever their overall effect on competition, one purpose of these cartels may have simply been to resolve the time consistency problem - thus effectively committing to consumers that new movies would not be available at lower prices for certain substantial lengths of time following their current exhibitions.

Finally looking ahead of our study, Nelson et al. (2007) and available descriptive data for years through 2008 indicate a slow but fairly steady decline in the average DVD window for major films since 1997 to about 19 weeks. Analysis of individual distributor strategies as windows have diminished may provide better distinction between possible models of industry window setting behavior.

A broader question for further research is whether firms in other competitive environments are able to control product release dates by coordinated behavior or other commitment devices. An analagous study to ours, for example, might be conducted in book publishing to understand how firms in that industry maintain the intertemporal price discrimination strategy they appear to rely upon (Clerides, 2002). 


\section{References}

Ausubel, L.M., and R. J. Denekere (1987), One is Almost Enough for Monopoly, The RAND Journal of Economics, Vol. 18, 255-274.

Bulow, J. (1982), Durable-Goods Monopolists, Journal of Political Economy, Vol. 90, 314-332.

Clerides, S. (2002), Book value: intertemporal pricing and quality discrimination in the US market for books, International Journal of Industrial Organization, Vol. 20, 1385-1408.

Coase, R. H. (1972), Durability and Monopoly, Journal of Law and Economics, Vol. 15, 143-149.

Conant, M. (1960), Antitrust in the Motion Picture Industry, University of California Press.

De Vany, A., and R. D. Eckert (1991), Motion Picture Antitrust: The Paramount Case Revisited, Research in Law and Economics, Vol. 14, 51-112.

Einav, L. (2007), Seasonality in the U.S. Motion Picture Industry, The RAND Journal of Economics, Vol. 38, 127-145.

Frank, B. (1994), Optimal Timing of Movie Releases in Ancillary markets: The Case of Video Releases, Journal of Cultural Economics, Vol. 18, 125-133.

Gul, F. (1987), Foundations of Dynamic Oligopoly, The RAND Journal of Economics, Vol. 18, 248-254.

Mortimer, J. (2007), Price Discrimination, Copyright Law and Technological Innovation: Evidence from the Introduction of DVDs, Quarterly Journal of Economics, Vol. 122, 1307-1350.

Nelson, R., C. Reid, and O. Gilmore (2007), An analysis of the out-of-market gap for DVDs in the US, Review of Industrial Organization, Vol. 30, 303-23.

Owen, B., and S. Wildman (1992), Video Economics, Harvard University Press.

Paul Kagan Associates (1994), European Home Video.

Prasad, A., B. Bronnenberg, and V. Mahajan (2004), Product entry timing in dual distribution channels: the case of the movie industry, Review of Marketing Science, Vol. 2, 1-18.

Screen Digest (2002), European Video: Market Assessment and Forecast, London.

United States v. Paramount Pictures, Inc., et al. 334 US 131 (1948).

Waterman, D. (2005), Hollywood's Road to Riches, Harvard University Press.

Waterman D., A.A. Weiss, and S-C. Lee (2008), Time Consistency and Seller Commitment in Intertemporal Movie Distribution: An Empirical Study of the Video Window, working paper, School of Economics, ANU. 